\title{
Ergonomic analysis of safety signs: a focus of informational and cultural ergonomics
}

\author{
Janaina Cavalcanti ${ }^{*}$ and Marcelo Soares \\ Universidade Federal de Pernambuco. Departamento de Design. Av. dos Reitores, s/n, Cidade Universitária- \\ Recife-PE, Brasil. CEP: 50670-901.
}

\begin{abstract}
This paper presents the results of a research carried out in the states of Pernambuco and Rio Grande do Sul, Brazil about differences and similarities in the graphic representation of safety signs at factories of food, steel, shoes and construction/building industries, together with their workers' opinions on the security signs. The overall results show differences in the sign structure across the states, confirming the influence of cultural differences on the design of safety signs, which must be taken into account during the design process.
\end{abstract}

Keywords: Keyword one, keyword two, keyword three, keyword four, keyword five

\section{Introduction}

Globalization has increasingly reduced the barriers between countries and their distances in the world. What is said, created and produced in a country is almost instantly transmitted to others. But while such means as the Internet, for example, make it easier to distribute the global information, the same design for different cultures is still very difficult. It is considered that the use of visual message with a more universal character, has acquired greater importance each day. Add to that social issues such as illiteracy, as an element that make it hard to communicate through signs.

The visual message can occur through verbal messages (alphanumeric characters) and / or mental pictorial landscapes (illustrations), and constitute the main-pal means of imparting knowledge. In this function can be used to communicate and / or request procedures in any environment, included in the industry, aimed at ensuring greater safety and productivity systems.

However, it is important to note that the ways in which information appears to the reader, it means the systematic delivery of your presentation have great influence on user behavior on the activity being performed. Therefore, for greater safety and efficiency, you need all the attention focused on the quality of infor-mation, as well as how the reader will perceive and respond to them.

Considering the ergonomics as a discipline, supported by scientific data, has its focus on the interface of humans with their work environment and leisure, it is possible and important to consider it responsible for the study of interactions of the human system-message visual. For both tools appear as printerfissile [i] cultural ergonomics, which aims to study all the characteristics intrinsic to the individual's culture, how it manifests itself and influences their behavior and [ii] that informational ergonomics concerned with the structure of signs and their influence on the effectiveness and efficiency of information presented [3] .

Based on the factors discussed above, associated with the fact that despite the relevance of this issue, this type of material has been little researched in some regions, that he realized the necessity of developing this article aims to show the importance of taking into account the structural aspects of messages and cultural environment where it is inserted.

\footnotetext{
${ }^{*}$ Corresponding author: Cavalcanti, Janaina. E-mail: cjanaina@gmail.com.
} 


\section{Informational and Cognitive Ergonomics}

Ergonomics comes from the informational purpose of making use of the principles of Information Theory, send the right information to the right person at the right time, effectively and efficiently. Thus, satisfies the user always respecting their diversity in terms of abilities and limitations.

To achieve its goal, the ergonomics macional includes infor-cognition and perception, and covers aspects of language and verbal and iconographic study of the communication channels of the human [3], taking into account, according to [2]: (i) visibility, (ii) clarity and (iii) readability or understandability

The Cognitive ergonomics refers to mental processes as they affect interactions among humans and other elements of a system. Since personal factors exert influence in being, each individual has its own cognitive style. This causes a number of factors can affect the performance required. The main object of study of ergonomics informacional is the message. Depending on what you want to communicate, the message, according to [1], can be classified as:

(i) information, when information prevails in the message, which occurs, for example with bank statements;

(ii) instructor, which occurs when the sender tries to that influence the behavior showing the effects of the influenced must have, as occurs for example when a person asks for it to reach the goal of $X$ and parts produced;

(iii) stimulating or motivational when it tries to influence the receiver, showing the convenience of behaving in a way - using the previous example would be when, if you ask a guy he reaches the goal of $\mathrm{X}$ produced parts, telling him that this will the company to sell more and provide greater gratification.

About how the visual message presents, according to [7] this can be:

(iv) verbal: when being for alphanumerics caracteres;

(v) pictorial : consists of image.

Twyamn reconhece também a associação destas duas formas de representação, considerando-as verbal-numérica, ou pictórica-verbal/numérica.
According to [4], visual messages, according to the type of information designed to transmit classified into:

(i) regulatory - are intended to inform the rules oh the systems and/or procedures that you must follow to maintain its regulation;

(ii) indicative of safety condition - giving users information about situations where, in a state of emergency, you can find safety;

(iii) mandatory action - requires the user to obey the rules;

(iv) prohibition - to inform actions that are not allowed ;

(v) hazard warning - warning about the risks;

(vi) hazard identification isolates the hazardous environment where users should not be circulated.

It is important in the study and development of information-sign, pay attention to consider the factors of individuals besides the message's factors, since the interpretation of visual messages is influenced, and possibly modified by psychological factors, emotional, cognitive, cultural expectations and the environment (influence of the environment where the person lives or is found). These aspects will be studied next..

\section{Cultural Ergonomics}

The culture, customs and traditions and the environment where the individual is inserted embeds features that will influence their behavior, their personality-ability your "self" and consequently the performance of any activity.

According to [5], cultural ergonomics is the branch of ergonomics approach which considers situations and characteristics based on cultural diversity, applying it to the system design, implementation and evaluation. That is, one in which the traits and environmental constraints vary according to culture and that this influences the perception, behavior, and acceptability. This means that when it comes to information, which is significant for a culture or individual may not be significant to another, or what is still well regarded and accepted by a individual of a particular age group or eco-nomic may not have credibility and acceptability to another.

Aiming to understand how culture influences the reading of the signs and the role of the subculture in this process was realize a research out a field survey, whose methodology and results-development will be presented below. 


\section{Field Research}

For the development For the development of field research was choosing eight companies from four different areas of activity in two Brazilian states with different characteristics - Pernambuco and Rio Grande do Sul - so that each business sector had a company in each state for further intersection and data analysis.

The safety signs corporate participants in the study were raised and categorized as safety posters, educational messages and warnings, following a theoretical approach based on analytical models, parameters and taxonomy proposed by [6], [7] and [6].

In this analysis, the variables to consider are the nature of informational, educational and graphics. The graphics (like the way the sequences are visually organized) will be described by observing the following variables:

- Mode of Symbolization : it refers to the way the graphic languages is visually symbolized may be verbal/numerical, pictorial or verbal - numerical;

- Structure of the illustration refers to the use or absence of edges, lines or other element on the icons delimitando its area classified as being in open or closed figures, as can be seen below (Figures 1 and 2).
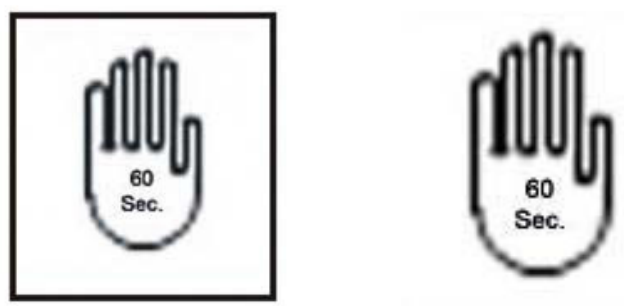

Figure 1: Closed Image and Opened Image.

- Ilustatrion Style: is the type of illustration that is used to represent procedures. They can be: photographic style (which precisely depicts objects or aspects of the real world, but are expensive), design (have a medium degree of naturalism and are very versatile), schematic (with a low degree of naturalism and represents the reality as it is understood and nit as it really is, as is the case of pictograms) and shadow or silhouette (which is very simplified and have a low degree of naturalism).

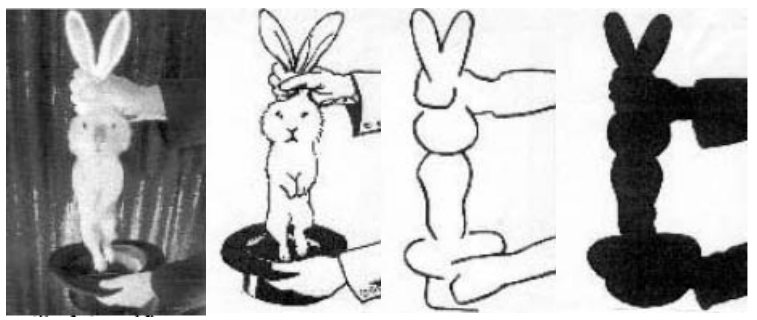

Figure 2 - Styles of illustration. From left to right: photo, design, schematic and shadow or silhouette [8].

- Content of illustration: it can be descriptive, prescriptive or proscriptive.

- Symbolic Elements: they the conventions used to represent, for example, action with arrows and slash through denial;

- Warning word's: use of words to draw the reader's attention, such as danger, caution, warning, among others;

- Visual separation of elements: how are the graphics space, lines and / or edges, which are used to separate / emphasize the illustrations;

- Risk desciption : the presence or absence of text that describ the risk involved;

- Description of outcome : presence or absence of description of the consequences arising from the risk posed;

- Direction/instrution or action : presence or absence of a text explaining the action to be performed;

- Text Presentation: the way in which the text is presented in relation to the illustrations. It can be legends (when the text and image form a unity, a single block), text-run (the illustrations are inserted in the text or no illustrations), and label (the text is inserted into the picture);

- Attributes: are the graphics (eg font size, bold, italics) that may be used to emphasize or prioritize specific aspects or elements of the text .

The results were compared analyzing the existence of influence of different cultures in the structure of visual messages in the eight companies which areas are: food, metallurgy, shoe and construction in the states Pernambuco and Rio Grande do Sul.

Interviews were conducted with a sample of 40 workers per firm in order to collect data on: the workers, their needs and problems of information that could influence the performance of their activi- 
ties. For this approach, interviews were conducted based on a questionnaire prepared previously.

In the sample were found Picture messages like: pictogram, poster and map security risk (graphical representation on the layout of the company, the location of all the risks in different workplaces, their classification and level of danger).

The varieties of structural elements of the messages were analyzed taking into account the following variables: [i] mode of symbolization, [ii] Illustration - divided into structure, style, content, symbolic elements and elements of visual separation and [iii ] text (divided into word of warning, risk description, description of the result, direction, instruction or action, presentation and attributes).

\section{Main results}

From the analysis of signs firms from Pernambuco and Rio Grande do Sul were found many many similarities and some differences, as described below.

Regarding the mode of symbolization, the state of Pernambuco hás the highest incidence of use verbal/numerical -pictorial $(62,5 \%)$ and in RS, the verbal/numérico $(52,94 \%)$, but , acoording to the literature, the pictorial is the most recommended.

Even in this state, we observed the predominance of the symbolic circle, with $46.17 \%$, followed by diagonal, with $30.77 \%$. In Rio Grande do Sul, the predominant element was the arrow, present in $45.45 \%$ of the samples, while the circle came in second with $36.36 \%$. The differences could also be observed in the words of warning. In Rio Grande do $\mathrm{Sul}$ is the most common word Warning (45\%) and Pernambuco, Caution (40.68\%). As for the attributes for the hierarchy of information, the font size was the most used in Pernambuco $(46.85 \%)$, while in Rio Grande do Sul was the color (51.06\%).

In terms of information content, there was a higher incidence of descriptive images in Pernambuco $(52.63 \%)$ and prescriptive in Rio Grande do Sul $(56.25 \%)$. As the form of presentation, the title was more present in Pernambuco (40.43\%), and run over text found in Rio Grande do Sul (37.04\%).

Regarding the Structure of illustration, in the two states the closed structure was the higher incidence (83,10\% in Pernambuco and $75 \%$ in Rio Grande do $\mathrm{Sul})$. The same happens with the variable style of illustration, where the Squematic style had higher incidence $(75.34 \%$ in $\mathrm{PE}$ and $87.5 \%$ in $\mathrm{RS}$ ), and among the elements of Visual Separation, of which space is used both places $(46.38 \%$ in Pernambuco and $41.38 \%$ in RS).

In variable Risk Description, the ConsequencesDescriptions and Instruction both regions have made more use of signs in Education (72.32\% in Pernambuco and $76.47 \%$ in Rio Grande do Sul).

In the previously presented we can see that the nine variables taken as a reference for analysis, five had different results between regions.

In the approach of the workers, first we drew up the profile of each sample, then collect the opinions about the visual messages specifically. It was noticed that the sample consisted mostly of males (72.5\%), whose age was a higher incidence of 20 to 25 years $(42.5 \%)$ follow the 26 to 30 years $20 \%$.

The education level of workers in Pernambuco is complete medium $(66.8 \%)$ and with disabilities make up only $8.75 \%$ of the sample, most of them are visually impaired. The birthplace is the predominant state itself. This data was important in the study, since through according with this we can know the extent to which workers in each region is distinct from other cultures influential of his birthplace. In Rio Grande do Sul, the predominant sex was male but the predominant age group was between 34 and 52 years $(38 \%)$.

The educational level found for the worker of Rio Grande do Sul was the school-based mental incomplete $(33.07 \%)$, therefore lower than that of workers in Pernambuco.

With regard to accidents, in the northeastern state's average of $53.1 \%$ of users who not suffered injuries while in the southern state of this index is $74.2 \%$, as can be seen.

Turning to the characteristics of the message that most attracted the attention of readers of the visual message in Rio Grande do Sul were in descending order: color, illustration, text and structure, and Pernambuco, illustration, color, text and structure. On the other hand, about what they liked least in signaling, the Pernambuco highlighted the lack of standardization and the Southest the quantity of plates, which, according to them the number claiming found was insufficient to the need.

The table 1, presents a summary of the main analysis of data collected in the approach of workers . 
Table 1

Comparing the characteristics / preferences of users by state.

\begin{tabular}{|c|c|c|}
\hline \multirow[b]{2}{*}{ Item } & \multicolumn{2}{|c|}{ Characterics / Preferences } \\
\hline & Pernambuco & $\begin{array}{c}\text { Rio Grande do } \\
\text { Sul }\end{array}$ \\
\hline $\begin{array}{l}\text { Most Respon- } \\
\text { dents }\end{array}$ & $\begin{array}{c}\text { Men }(72,5 \%) \\
17 \text { a } 25 \text { yeras } \\
\text { Complete sec- } \\
\text { ondary Shooling } \\
(66,8 \%)\end{array}$ & $\begin{array}{c}\text { Men }(76,3 \%) \\
34 \text { a } 52 \text { ages } \\
\text { Incomplete Prima- } \\
\text { ry Education }(33,07 \%)\end{array}$ \\
\hline $\begin{array}{l}\text { Features that } \\
\text { stands out }\end{array}$ & $\begin{array}{c}\text { Ilustra- } \\
\text { tion }(49,7 \%) \\
\text { Color }(30,5 \%) \\
\text { Text }(15,3 \%) \\
\text { Structure }(4,5 \%)\end{array}$ & $\begin{array}{c}\text { Color }(38,2 \%) \\
\text { Text }(33,7 \%) \\
\text { Ilustration }(14,6 \%) \\
\text { Structure }(13,5 \%)\end{array}$ \\
\hline $\begin{array}{l}\text { Think is rle- } \\
\text { vant the use of } \\
\text { signalization }\end{array}$ & $91,9 \%$ & $89,9 \%$ \\
\hline Most Like & Colors & Informattion \\
\hline Less Like & $\begin{array}{l}\text { Lack of standar- } \\
\text { disation }\end{array}$ & Number of signs \\
\hline $\begin{array}{l}\text { Suffered an } \\
\text { accident }\end{array}$ & $46,9 \%$ & $25,8 \%$ \\
\hline
\end{tabular}

We can see in Table 1, a distintion in both states. Cruzing the results of the two analisis (users and signs), we can see that this profile influences the structure of signs.

The culture and subculture affect the behavior of individuals and are also influenced by them (being represented here by the normal rules, for example).

\section{Comments and Recommendations}

Based on the study of the structure of the messages was possible to prepare a discussion of the characteristics of signals in each state. The analysis of the variables that form the visual message separately is of great importance, because through it we can see if some type helps or hinders reading the message, as was the case of the closed structure, which was present in all messages with well accepted.

Through interviews it was possible to draw the workers profile in each region and the influences inherent in them and acquired throughout life.

An intersting fact observed was that although the education level of workers in Rio Grande do Sul (incomplete primary) to be lower than in Pernambuco (complete medium) which creates a tendency to think that there is a greater presence of pictorial messages in the first state than in the second, the study showed otherwise. However, the approach of users noticed also that how lower the educational level of the gauchos, less importance is given to the illustration, which explains the higher incidence of verbal symbolization mode / number of this state.

Others importants conclusions are:

- the more education, less importance is given to the text in Rio Grande do Sul and Pernambuco is given high importance to the image indeoendent of schooling;

- the disabled given more importance to the text than the not disable;

- Who are familiar only read the messages sometimes ;

- most individuals of the female RS suffered an accident.

From this research, it was a series of recommendations aimed at improving the design of visual messages, such as:

- presents closed structure of visual messages;;

- Best be illustrated with Schematic Design;

- the font must have a clean look;

- to prioritize the information should be used bold instead of italic;

- the visual messages should be used only when it is necessary at risk of loose the credibility of the same;

- is important and accepted the use of color, as long as there is harmony, psychology and correlation;

- uniformity of the messages makes it clear its understanding, and contribute to their acceptance.

\section{Conclusion}

It is hoped that this study will contribute to the design of safety messages, and obeying the ergonomic parameters they can perform their function in an increasingly more efficient.

Finally, we wish to place on record that consider the skills, needs and characteristics of individuals and regions in the development of visual messages is not just a question of survival in the competitive modern world, it is a matter of human respect and social responsibility. 


\section{References}

[1] Bernardes, C. Sociologia Aplicada à Administração: gerenciando grupos nas organizações. São Paulo, Atlas, 1995. pp. 35-88.

[2] Epstein, I. Teoria da Informação. São Paulo, Edgard Blümcher, 1995.

[3] Martins, L. B. and Moraes, A. Ergonomia Informacional: algumas considerações sobre o sistema humano-mensagem visual. In: Gestão da Informação na Competitividade das Organizações. Recife: Editora Universitária da UFPE, 2002 v.1 p.165 a 181 .

[4] Padovani, S. Apostila de Acompanhamento da Disciplina Ergonomia Informacional. Recife, UFPE, 2003

[5] Smith-Jackson, T. L. S. and Wogalter, M. S. Applying cultural ergonomics/Human Factors to safety information research. In: Congresso Latino-americano de Ergonomia, VII; Congresso Brasileiro de Ergonomia, XII; Seminário Brasileiro de Acessibilidade Integral, I. 2002 Recife. Anais ABERGO 2002, CD. Recife: ABERGO, 2002.
[6] Spinillo, C. An analytical approach to procedural pictorial sequences. Reino Unido, 2000. 235p. (Doutorado (PhD) - Department of Typography \& Graphic Communication, The University of Reading).

[7] Twyman, M. A Schema for the study of graphic language. In P.A. KOLERS, M.E. WROLSTAD and H.BOUMA, ed. Processing of visible language 1 . New York, London: Plenum Press, 1979, pp.117-150

[7] Twyman, M. Using Pictorial Language: a discussion of the dimensions of the problem. In: DUFTY, T.M. \& WALLER, R., ed. Designing Usable Texts. Orlando, Florida: Academic Press, 1985 , p. $245-312$

[8] Wanderley, R. G. and Coutinho, A. M. Estilo de Ilustração. In: Congresso Nacional de Iniciação Cientifica em Design da Informação, Recife, 2003. 